Motor Vehicles and their Engines

Fifth edition, by Norman G. Shidle and Thomas A. Bissell, with the assistance of Tench Francis. Pp. vii +339. (New York: D. Van Nostrand Co., Inc.; London: Macmillan and Co., Ltd., 1941.) 16s. net.

GOR the student who is interested in learning to

do practical repair work on motor-vehicles, the first consideration is that he should obtain a comprehensive knowledge of the construction of the vehicle and its engine and equipment, and also of the principles which have governed its design. Formulæ and calculations are of secondary importance, as the repairer's work is the readjustment or renewal of parts which have gone out of order in service.

This book is designed for the student entering upon the subject for the first time, and is equally valuable for the owner-driver who wishes to take a close practical interest in his car or the transport manager whose duty it is to be familiar with the details of the fleet of vehicles under his supervision. Although it deals with current American practice, it is none the less useful in Great Britain on that account, as the main features of design are well standardized. The descriptions and explanations are given in terms which will present no difficulty to any class of reader; technicalities have been reduced to a minimum and fundamentals are stressed in the simplest possible manner.

In each section of the work, a sufficient outline of the fundamental theory is given, and special mention may be made of the way in which the electrical equipment is introduced by statement of the theory of magnetism and electricity. Then follows the descriptive and explanatory text relating to the parts under discussion, and this generally terminates with a description of the mechanical troubles most likely to occur. In this way the student is led directly from theory and construction to the actual contacts, whether formal or informal, which he will make with the problems of maintenance and repair, and prepare him for the best use of the instruction handbook issued with each vehicle.

\section{Bibliographia Primatologica}

A Classified Bibliography of Primates other than Man. Part 1: Anatomy, Embryology and Quantitative Morphology ; Physiology, Pharmacology and Psychobiology; Primate Phylogeny and Miscellanea. By Theodore C. Ruch. (Historical Library, Yale Medical Library, Publication No. 4.) Pp. xxvii + 241. (Springfield, Ill., and Baltimore, Md.: Charles C. Thomas, 1941.) 8.50 dollars.

THE scope of Dr. Ruch's bibliography is fully indicated by its title. It makes available, both to laboratory workers and to others who are interested in the subject, a comprehensive list of published papers on the anatomy, physiology, pharmacology and psychobiology of monkeys and apes.

The anatomical section deals first with embryology and general morphology, and then with the various systems of the body. The physiological and pharma. cological papers are also classified primarily according to the body systems, while the section on psychobioiogy is organized by broad subject headings. The further subdivision of the various sections is excellent, and it is a simple matter to find whether or not papers have been published on any aspect of the primates. There is considerable cross reference, and there is an index of authors which includes some two thousand names. A very large number of individual papers are cited. The abbreviation of journal titles is according to the World List of Scientific Periodicals.

Dr. Ruch deserves the warmest thanks of students of the primates for having successfully undertaken a most laborious and painstaking task. "Bibliographia Primatologica" represents both a great public-spirited achievement and a monument to what is already known about man's closest relatives in the animal world. His work will lighten the effort not only of research workers already engaged in this field of study, but also of recruits to the subject.

\section{Thermionic Valve Circuits}

By Dr. Emrys Williams. Pp. viii +174 . (London : Sir Isaac Pitman and Sons, Ltd., 1942.) 12s. $6 d$. net.

DASED upon the lecturing experience of the Bauthor, this book presents an outline of the theory of the operation and design of thermionic valve circuits in a form suitable for university students during the final year of their degree course in electrical engineering. The treatment is confined to a consideration of the principles of the use of valves in their various forms in radio transmitters and receivers, and no attempt is made to describe how the different functions are realized in practice. While it is assumed that the reader has a knowledge of alternating current theory and the associated mathematics, a short summary of the vector algebra required for this subject is given in the first chapter. Subsequent chapters deal with the valve, and its use as an amplifier, oscillator, detector, frequency changer and modulator. The treatment throughout the book is very clear and straightforward, and appears to be almost entirely free from errors or misprints.

While there are one or two places in which the descriptive matter might have been expanded, the author has probably been wise in keeping brevity before him as one of his main objectives. Certainly the modern, hard-pressed university student will appreciate this in a book which is admirably suited to his purpose.

\section{The Cathode Ray Tube and its Applications}

By G. Parr. Second edition. (First published under the title "The Low Voltage Cathode Ray Tube".) Pp. viii +180 . (London : Chapman and Hall, Ltd., 1941.) 13s. $6 d$. net.

HIS book was first published in 1937 under the title "The Low Voltage Cathode Ray Tube", which was somewhat misleading in view of the fact that it deals with the various forms of cathode ray tube operating at accelerating potentials up to about 5,000 volts. The first three chapters deal with construction and operation of cathode ray tubes, their focusing arrangements and the interpretation of the patterns traced on the screen for various currents or voltages applied to the deflecting system. After two chapters devoted to time base circuit arrangements, the remaining chapters deal with the application of the tubes to various radio engineering, including television, and industrial uses. The book concludes with an appendix on photography and a most valuable classified bibliography of the subject.

The publishers are to be congratulated on the general production of this book, especially on making it much slimmer by the simple expedient of halving the thickness of the paper. The book should prove most useful to all those-and they are very many indeed just now-whose duties bring them very frequently into contact with cathode ray tubes. 